\title{
Medicinal plants in Butalejja District, Eastern Uganda: plants, medical importance, conservation and Medicinal Traditional Knowledge
}

Jamilu. E. Ssenku ( $\sim$ jssenku@gmail.com)

Islamic University in Uganda

Shaban A. Okurut

Islamic University in Uganda

Aidah Namuli

Islamic University in Uganda

Ali Kudamba

Islamic University in Uganda

Godfrey Wasige

Islamic University in Uganda

Hussein M. Kafeero

Islamic University in Uganda

Abdul Walusansa

Islamic University in Uganda

\section{Research Article}

Keywords: Traditional medicine, Ethnomedicine, indigenous medicine knowledge, Ethno-botanical, Butalejja,

Posted Date: May 27th, 2021

DOI: https://doi.org/10.21203/rs.3.rs-566869/v1

License: (c) (i) This work is licensed under a Creative Commons Attribution 4.0 International License. Read Full License 


\section{Abstract}

Background: Currently, the global consumption of herbal medicine is increasing steadily, incurring extinction risks to the medicinal plant species. Uganda is one of the top ten countries with alarming levels of loss of medicinal plant biodiversity, and erosion of the associated Medicinal Traditional Knowledge (MTK). This study documented medicinal plant species, and examined the approaches used in preventing extinction of these species and the associated MTK in Butalejja district.

Methods: A cross - sectional study design was adopted to conduct an ethnopharmacological survey, using semistructured questionnaires administered to purposively selected herbalists. Simple descriptive statistics were adopted for data analysis using STATA version-15.0.

Results: A total of 133 medicinal plant species, belonging to 34 families and 125 genera were identified. Most species belonged to family Fabaceae (22; 65\%), and Solanaceae (10;29\%). Leaves were the commonest organ used (81; 80\%), followed by roots $(15 ; 15 \%)$. Medicinal herbs were mainly administered orally as decoctions $(100 ; 34.6 \%)$, and infusions $(45 ; 16 \%)$. The most cited diseases treated were cough $(24 ; 7.74 \%)$, Ulcers $(23 ; 7.42 \%)$, and Malaria $(14 ; 4.52 \%)$. Medicinal plants were majorly harvested from homestead farms and roadside vegetation, with wetlands being the least cited habitat. Efforts to stop the extinction of medicinal plants and MTK were inadequate.

Conclusion and recommendations: There was high dependency on medicinal plant species for primary healthcare and income generation. Noted also was the accelerated loss of medicinal plant biodiversity due to habitat destruction, especially in swamps. The conservation of medicinal plants and MTK was largely attributed to traditional cultural values. There is need for validation of efficacy and safety of key medicinal plants identified in this study, to support their future adoption in clinical medicine and pharmaceutical industries. Inclusion of traditional cultural ideals in national biodiversity conservation programs is warranted.

\section{Background}

Plants have been used for their curative properties since antiquity (Rajeswara Rao, 2016; Ojha et al., 2020). Consequently, human medicine is so linked to plant biodiversity that most of the current modern medicines were first derived from medicinal plants (Kiguba et al., 2016). Medicinal plants are wild and cultivated plants used in traditional and modern medicine (Rajeswara Rao, 2016). Across the centuries, the global rate of use of medicinal plants has been increasing, more so in developing countries (Tabuti et al., 2012) (2). This is mostly attributed to the fact that medicinal plants are readily available, widely accepted by many cultures, perceived to be safe and efficacious (Chinsembu \& Hedimbi, 2010). Throughout the world, local people utilize wild plants for medicinal purposes (Wanjohi et al., 2020) at an estimated prevalence of use ranging between $50 \%$ and $95 \%$ (Pan et al., 2019), Higher prevalence of use estimated at $80 \%$ has been reported in rural communities in developing countries. Further still, the prevalence of use is equally traced in developed countries such as USA (Rashrash et al., 2017), where health care facilities are in place and up to date. Due to this high demand for herbal medicine, and other factors, over 15,000 medicinal plant species are at risk of extinction (World Health Organization, 2004) and about $20 \%$ of the wild medicinal plants have already been nearly exhausted (Ross, 2007) majorly due to indiscriminate collection and overharvesting from their natural habitats (Phondani et al., 2016).

Medicinal plants form an important part of health care especially for the rural communities in Uganda owing to limited access to medical facilities; inadequate medicines and other medical supplies; shortage and low motivation of human resource at the available medical facilities; poverty, thus inability to afford Western medicine; socio-cultural barriers; and wide acceptance of traditional medicines (Kamatenesi-Mugisha \& Oryem-Origa, 2007; Nalumansi et al., 2014). They are collected from a variety of habitats especially wild bush using several harvesting techniques some of which are destructive (Tugume \& Nyakoojo, 2019). This unsustainable utilization of medicinal plants is currently fueled by the proliferation of largely unregulated herbal medicine selling in urban centers. This massive trade and consumption of medicinal plants poses risks to the conservation and preservation of medicinal plant species (Chen et al., 2016). Consequently, Uganda is 
now among the countries at highest risk of future extinction of numerous medicinal plant species (Zerabruk \& Yirga, 2012; Chen et al., 2016). Unfortunately, this is happening at the time when Uganda's government efforts are geared towards up scaling the use of herbal medicine and is in the process of integrating it into the main health care system (WHO, 2013; Uganda Gazette, 2015).

Butalejja, is one of the rural, remote districts in eastern Uganda with relatively poor infrastructure and service delivery; It is deficient in pharmacies, licensed private drug shops, and affordable private clinics (Rahimi et al., 2019). Thus, the district is characterized with wide spread use of medicinal plants (Mbonye et al., 2006; Tabuti et al., 2012; Nuwaha et al., 2013) to treat various ailments and to generate income. Despite the wide spread use of medicinal plants, the TMK in this district is reported to be eroding steadily (Cox, 2000) (16). Also, some threats to plant biodiversity conservation, such as; climate changes, and widespread herbal medicine trade have also been reported. Thus, in this study, we aimed at documenting medicinal plant species, the ailments they treat, their modes of application, and the approaches adopted to conserve these species and the associated MTK in Butalejja district. The aim was to generate knowledge that highlights need and guide formulation of policies and mechanisms that could promote sustainable utilization of medicinal plants and conservation of TMK, to protect future generations against dire health consequences of medicinal plants extinction.

\section{Materials And Methods}

\section{Study area}

This study was undertaken in three villages, of Budoba, Bubuhe and Mulanga, located in Busaba sub-county in Butalejja district. The villages are located in the rural, remote parts of Eastern Uganda, $38 \mathrm{Km}$ from Mbale city and $247.8 \mathrm{Km}$ from the capital city Kampala, within geographical coordinates of $33^{\circ} 45^{\prime \prime} \mathrm{E}$ to $33^{0} 53^{\prime \prime} \mathrm{E}$ and $0^{0} 51^{\prime \prime} \mathrm{N}$ to $0^{0} 55^{\prime \prime} \mathrm{N}$ (Fig. 1) and at an average elevation of 1143 meters above sea level. It experiences a tropical climate, with annual average rainfall of 1183 $\mathrm{mm}$ that is bimodally distributed, with the highest peaks occurring in April-June and October-December. The mean monthly temperature ranges between $10^{\circ} \mathrm{C}$ and $27^{\circ} \mathrm{C}$. The vegetation majorly comprises of wetlands, few thickets and grasslands and scarcity of forests. Considerable changes in vegetation are taking place due to widespread cultivation of food crops such as rice and population pressure.

\section{Demographic characteristics of the population.}

The people majorly belong to the Banyole ethnic group and the main language spoken is Lunyole. The community is both rural and semi urban, characterized with relatively high levels of monetary poverty and illiteracy (De Sherbinin et al., 2015). Most of them are peasant farmers, dealing majorly in wetland-based rice growing and small-scale businesses for livelihoods., The community in Busaba sub-county faces limited access to medical facilities as there is only one Healthy Centre IV hospital located at the headquarter. In this study, most of the selected respondents had attained primary education ( $49 ; 62 \%)$, followed by secondary education $(28 ; 35 \%)$. Males were $(59 ; 74 \%)$, and females $(21 ; 26 \%)$. The majority of the participants $59,(74 \%)$, were males, while $21,(26 \%)$ were females. Most participants $36,(45 \%)$, fell in the age category of 31-40 years while the minority were in the age categories of; $10-20,71-80$ and $81-90$ years, 1, (1\%) each.

\subsection{Study Design and sampling technique}

The study was undertaken between July 2020 and March 2021 in conformity to the national guidelines for the conduct of research in the COVID-19 era established by the Uganda National Council for Science and Technology (UNCST, 2020). A cross-sectional study design was adopted to conduct an ethnopharmacological survey, using semi-structured questionnaires and Key informant interviews. Eighty renown Traditional health practitioners (THP), were purposively identified from the three villages under the guidance of local council chairpersons and the snowball technique. Participants were subjected to pretested, semi-structured questionnaires and key informant interviews. For each medicinal plant, the respondents were asked to provide the local name, the ailment treated, part used and mode of administration. The non- 
generic names were either in Lunyole (Lun), Luganda (Lug), or English (Eng). The availability and conservation strategies of medicinal plants and TMK, plus the associated challenges were also investigated. the availability status, perceived reasons for availability status.

We collected voucher specimens of the medicinal plant species listed following standard procedure described by Martin (1995). The species names and families were determined at the Makerere University herbarium and verified using a comprehensive plant data base (The Plant List, 2021). The voucher specimens were deposited at the Islamic University in Uganda Herbarium. The filled questionnaires were checked for consistency and completeness before the final data processing and analysis. Hard copies of the data from the interviews and questionnaires were kept in locked file cabinets that were only accessible to the research team. All data was entered in Microsoft excel and stored in a password protected computer.

\subsection{Data analysis}

Simple descriptive statistics were adopted for data analysis using STATA version-15.0. The results were summarized in form of bar graphs and tables. The graphs were generated with GraphPad Prism 8.0 soft (GraphPad Software, Inc., San Diego, CA).

\section{Results}

\subsection{Diversity of medicinal plants}

We identified a total of 133 medicinal plant species belonging to 34 families and 125 genera in the three counties studied (Table. 1). The highest number of medicinal plants were in the family Fabaceae; 22 (65\%), Solanaceae; 10 (29\%), Asteraceae; 10 (29\%), Euphorbiaceae; 6 (18\%) and Myrtaceae; 6 (18\%). The major plant part used as medicine was the leaf; $81(80 \%)$ followed by the root; $15(15 \%)$. Out of the 133 medicinal plants recorded, herbaceous species were dominantly used. The number of diseases treated by each species varied widely, with some species cited to be treating more than four diseases; such as Persea americana Miller, Rumex usambarensis (Dammer), Allium sativa L, Mangifera indica L, Aristolochia elegans Mast, Aloe vera (L.) Burm.f. among others.

\subsection{Modes of administration and diseases treated}

Drinking of decoctions (extracts obtained by boiling in water), was the commonest method of administration, 100 (34.6\%); followed by drinking of infusions, 45 (16\%); and the use of concoctions, 24 (8.3\%) (Table 1). The identified plants were found to treat 101 physical ailments and spiritual diseases. The study revealed cough as the ailment treated by most of the plant species $(7.74 \%)$ followed by ulcers $(7.42 \%)$, malaria $(4.52 \%)$, candidiasis $(3.87 \%)$ and stomach ache (3.87\%) (Table 2). Diseases whose frequency citation was between 1-4 were categorized among "others" of which 44, 25, 9 and 5 had citation of 1, 2, 3 and 4 respectively. Most herbalists had some belief in spiritual powers, and thus some plants, such as Dyschoriste radicans (A. Rich.) Nees, and Chenopodium ambrosoides L., were being used in the treatment of spiritual ailments (Table. 2).

\subsection{Sources of medicinal plants and traditional medicinal knowledge (TMK)}

Homestead farms and roadside vegetation were cited as the commonest sources of medicinal plants, with each mentioned by 80 (100\%), of the THP. Others included; distant forests, 8, (10\%); markets, 7, (9\%); and spiritually protected forests, (ENGOLO). Wetlands were the rarest source of medicinal plants $5(6 \%)$. The most frequently mentioned source of TMK was the inheritance from parents and grandparents 80, (100\%). Experimentation (random selection and medicinal use of plants species without having prior knowledge of their effectiveness), was the least mentioned source of TMK, 5 (6\%) (Fig. 2). 


\subsection{Conservation of medicinal plants and traditional medicinal knowledge}

To ensure sustainability of herbal medicine use, most of the TMP, 59 (73\%) mentioned that they made efforts to conserve medicinal plants, while 21 (27\%) mentioned that they did not make any conservation efforts, besides abiding to the communal restrictions. Preservation of spiritually protected forests, locally known as "ENGOLO" was the most frequently mentioned conservation strategy, 80 (100\%); while compliance with government laws and policies was the least mentioned approach, 4 (5\%). The results are summarized in Fig. 3.

\section{Discussion}

\subsection{Medicinal plants}

The medicinal plants used were found to belong mostly to the families; Fabaceae, Solanaceae, Asteraceae, and Euphorbiaceae, which were also reported in earlier studies, as families with high numbers of medicinal plants (Nankaya et al., 2019). This could possibly be attributed to their high diversity and abundance in the study area. In agreement with earlier studies by (Namukobe et al., 2011; Tabuti et al., 2012; Asowata-Ayodele et al., 2016; Aziz et al., 2018; Mujuru et al., 2020), the leaf was the most frequently used part of the medicinal plants, followed by the roots. However, this is in contradiction with the findings of Nankaya et al. (2019) and Wesolowska et al 2015; who reported roots, as the most preferred organ for use as medicine in rural communities. The high frequency of use of leaves could possibly be attributed to the fact that they can easily be harvested. Consequently, the notable usage of roots in our study community (as the second most preferred organ), is potentially attributed to their perceived high concentration of active ingredients; however, this incurs a threat to the sustainability of the medicinal herbs.

\subsection{Modes of administration and diseases treated}

We report a wide range of methods adopted in the administration of herbal medicines in Butalejja district. The plants were majorly used in a raw form without any further processing into improved herbal products. The medicinal herbal plants were majorly taken orally as decoctions and infusions. Earlier studies by Tugume and Nyakoojo (2019) and Bano et al. (2014), have also reported decoctions as a frequently used mode of application of herbal medicine. For spiritual ailments, the major mode of application was bathing of decoctions and inhalation of smoke got by burning the preferred plant organs. In the current study, we report a high number of diseases that were cited to be treated using medicinal plants. This number is higher than that reported in some earlier studies (Namukobe et al., 2011; Tabuti et al., 2012; Rakotoarivelo et al., 2015). This high number is reflective of lack of adequate access to modern medicine (Rakotoarivelo et al., 2015). This is luminescent of the extraordinary role played by medicinal plants in public promotion in the rural settings in Uganda.

\subsection{Sources of medicinal plants and TMK}

Traditionally, medicinal plant materials are mainly collected from the wild (Chen et al., 2016). In contrast with the latter, our findings revealed that the medicinal plants were majorly collected from homestead-farms. This could be attributed to the widespread destruction of wild habitats of plants, especially wetlands, through cultivation of paddy rice; population explosion due to early marriages and high school drop-outs rates; and the burgeoning commercialization of herbal medicine which is leading to over-exploitation. The over-exploitation of medicinal plant species has also been pointed out by Shumba et al. (2009), as one of the major driving factors for medicinal plant species scarcity in communities. The study revealed that conservation of indigenous traditional medicinal knowledge is commonly inherited from elders, both orally and through practice. This has also been reported to be predominant in other tribal societies of tropical Africa (Gumisiriza et al., 2021). Erosion of medicinal plant diversity and TMK is likely to be exacerbated by loss of medicinal plant habitats through wetland cultivation of rice, the migration of the youth to cities and town centers, cultivation of rice in wet lands, population pressure and lack of concerted effort to conserve 


\subsection{Conservation of medicinal plants and traditional medicinal knowledge}

Though the conservation of medicinal plants was highly threated by multiple factors such as habitat loss, population pressure and the growing dependance of herbal medicine as a source of income, their conservation was promoted by cultural beliefs and norms. These included; gender-restricted harvesting, mouth harvesting, night and naked harvesting, and the gazetting of spiritually protected forests (ENGOLGO) for each clan, from which harvesting is only authorized by the clan head. Further, we observed that there was a common belief among many herbalists that the onus to conserve medicinal plants and the associated knowledge was a divine duty entrusted on them by ancestral spirits. Spiritual beliefs have also been reported to play a major role in conservation of resources (Dorm-Adzobu et al., 1991; Ntiamoa-Baidu, 1995). In addition, the predominant use of leaves as a preferred organ, contributes to sustainable utilization of medicinal plants, since in most cases, it eliminates destructive harvesting.

The study revealed a high traditional medicinal knowledge transfer through spiritualism and dreaming, which are not very much recognized in traditional medicine knowledge transfer and conservation. Though peer learning was also cited, it is likely to become minimal with increased commercialization of the herbal medicine industry, due to fear of competition among the herbalists. Notably missing was the adoption of technical training to the young generation as a means of conserving TMK. This points at complete lack of integration of herbal medicinal use into the health care system. Therefore, there is no reliable method of indigenous medicinal knowledge conservation in the study community; and thus, the need to devise reliable conservation measures to arrest the possible loss of TMK in the rural communities as also pointed out by Mujuru et al. (2020). Compliance with government laws and policies was the least mentioned strategy adopted by the herbalists in an attempt to promoted conservative utilization of medicinal plants. This might partly be attributed to ignorance about the laws, and/or lack of concerted efforts by the government to enforce the regulations that would safeguard medicinal plant biodiversity conservation.

\section{Conclusion and recommendations}

There was high dependency on herbal medicine for primary healthcare and income generation in Butalejja district (RCC/2019/GRP2/005). Majority of the medicinal plants belonged to the families; Fabaceae and Solanaceae, and they were most frequently used in managing some of the world's most killer diseases, such as; respiratory tract ailments and malaria. The conservation of medicinal plants, and the associated indigenous traditional knowledge, was strongly attributed to traditional cultural beliefs and norms.

There is need for laboratory-based experiments on the plants identified in this study to confirm their safety and efficacy. This would support the adoption of these plants in the global fight against the deadly diseases they were claimed to treat. Further, traditional cultural values should be incorporated into the national biodiversity conservation agenda, owing to the extraordinary role of culture in inspiring the conservation of medicinal plants and the TMK observed in this study.

\section{Declarations}

\section{Ethical considerations}

This study was approved by the institutional review board of the Islamic university in Uganda. Approval was also sought from Butalejja district, and from the authorities in charge of the respective villages. The research was conducted in conformity to the national guidelines for conduct of research in the COVID-19 era established by Uganda National Council for Science and Technology (UNCST) (2020). Participants provided voluntary informed consent prior to participation in the study. Respondents' identifiers were recorded in form of assigned codes instead of names to ensures anonymity. All information from the participants was kept confidential \& stored under lock and key. Electronic data was stored in pass word protected electronic files during data management and analysis. 
Availability of data and materials

Data sets generated and analyzed during this study are available from the corresponding author on reasonable request.

\section{Competing interests}

Authors declare no competing interests associated with this study.

\section{Funding}

Not applicable

\section{Authors' contributions}

"Jamil. E. Ssenku (JES)", "Shaban A. Okurut (SAO)", and "Abdul Walusansa (AW)" conceived the research idea, participated in data collection and analysis, and in writing of the primary draft of the manuscript. "Ali Kudamba (AK)", "Godfrey Wasige (GW)" and "Hussein M. Kafeero (HMK)" participated in data collection, advised on the data analysis, and were major contributors in writing the manuscript. "Aidah Namuli (AN)" was a major contributor in manuscript writing and data analysis. "JES" was additionally, a senior advisor and supervisor in the study. All authors read and approved the final manuscript."

\section{Acknowledgements}

Part of the funds used in this research were obtained as a small grant provided to our research team by the Islamic Development Bank (IsDB). We are thankful to Mss. Olivia Wanyana, and Mr. Godwin Anywar of Makerere University, for the support rendered to us during the identification of plant species.

\section{References}

Asowata-Ayodele, A. M., Afolayan, A. J., \& Otunola, G. A. (2016). Ethnobotanical survey of culinary herbs and spices used in the traditional medicinal system of Nkonkobe Municipality, Eastern Cape, South Africa. South African Journal of Botany, 104, 69-75. doi:10.1016/j.sajb.2016.01.001

Aziz, M. A., Adnan, M., Khan, A. H., Shahat, A. A., Al-Said, M. S., \& Ullah, R. (2018). Traditional uses of medicinal plants practiced by the indigenous communities at Mohmand Agency, FATA, Pakistan. J Ethnobiol Ethnomed, 14(1), 2. doi:10.1186/s13002-017-0204-5

Bano, A., Ahmad, M., Zafar, M., Sultana, S., Rashid, S., \& Khan, M. A. (2014). Ethnomedicinal knowledge of the most commonly used plants from Deosai Plateau, Western Himalayas, Gilgit Baltistan, Pakistan. Journal of ethnopharmacology, 155(2), 1046-1052. doi:https://doi.org/10.1016/j.jep.2014.05.045

Chen, S. L., Yu, H., Luo, H. M., Wu, Q., Li, C. F., \& Steinmetz, A. (2016). Conservation and sustainable use of medicinal plants: problems, progress, and prospects. J. Chinese medicine, 11(1), 1-10. doi:https://doi.org/10.1186/s13020-016-0108-7

Chinsembu, K. C., \& Hedimbi, M. J. (2010). Ethnomedicinal plants and other natural products with anti-HIV active compounds and their putative modes of action. International Journal for Biotechnology and Molecular Biology Research, 1(6), 74-91. doi:https://www.researchgate.net/publication/228470522

Cox, P. A. (2000). Will tribal knowledge survive the millennium? Science, 287(5450), 44-45. doi: DOI: $10.1126 /$ science. 287.5450 .44 
De Sherbinin, A., Chai-Onn, T., Jaiteh, M., Mara, V., Pistolesi, L., Schnarr, E., \& Trzaska, S. J. I. I. J. o. G.-I. (2015). Data integration for climate vulnerability mapping in West Africa. 4(4), 2561-2582.

Dorm-Adzobu, C., Ampadu-Agyei, O., \& Veit, P. G. (1991). Religious beliefs and environmental protection: the Malshegu sacred grove in northern Ghana: Acts Press.

Gumisiriza, H., Sesaazi, C. D., Olet, E. A., Kembabazi, O., \& Birungi, G. (2021). Medicinal plants used to treat "African" diseases by the local communities of Bwambara sub-county in Rukungiri District, Western Uganda. Journal of ethnopharmacology, 268, 113578. doi:https://doi.org/10.1016/j.jep.2020.113578

Kamatenesi-Mugisha, M., \& Oryem-Origa, H. (2007). Medicinal plants used to induce labour during childbirth in western Uganda. J Ethnopharmacol, 109(1), 1-9. doi:10.1016/j.jep.2006.06.011

Kiguba, R., Ononge, S., Karamagi, C., Bird, S. M. J. B. c., \& medicine, a. (2016). Herbal medicine use and linked suspected adverse drug reactions in a prospective cohort of Ugandan inpatients. 16(1), 1-8.

Martin, G. J. (1995). Ethnobotany: a methods manual. doi: https://doi.org/10.1007/978-1-4615-2496-0

Mbonye, A. K., Neema, S., \& Magnussen, P. J. J. o. b. s. (2006). Treatment-seeking practices for malaria in pregnancy among rural women in Mukono District, Uganda. 38(2), 221.

Mujuru, L., Jimu, L., Mureva, A., Mapaura, A., Nyakudya, I. W., \& Muvengwi, J. (2020). Diversity of local knowledge on use of wild food and medicinal plants in communities around five biodiversity hotspots in Zimbabwe. Advances in Traditional Medicine, 20(4), 663-671. doi:10.1007/s13596-020-00512-z

Nalumansi, P., Kamatenesi-Mugisha, M., \& Godwin, A. (2014). Medicinal Plants Used in Paediatric Health Care in Namungalwe Sub County, Iganga District, Uganda. Nova Journal of Medical and Biological Sciences, 03(02), 1-10. doi:10.20286/nova-jmbs-030234

Namukobe, J., Kasenene, J. M., Kiremire, B. T., Byamukama, R., Kamatenesi-Mugisha, M., Krief, S., Dumontet, V., \& Kabasa, J. D. (2011). Traditional plants used for medicinal purposes by local communities around the Northern sector of Kibale National Park, Uganda. J Ethnopharmacol, 136(1), 236-245. doi:10.1016/j.jep.2011.04.044

Nankaya, J., Gichuki, N., Lukhoba, C., \& Balslev, H. (2019). Medicinal Plants of the Maasai of Kenya: A Review. Plants (Basel), 9(1). doi:10.3390/plants9010044

Ntiamoa-Baidu, Y. (1995). Indigenous vs. introduced biodiversity conservation strategies: the case of protected area systems in Ghana: Biodiversity Support Program.

Nuwaha, F., Musinguzi, G. J. B. c., \& medicine, a. (2013). Use of alternative medicine for hypertension in Buikwe and Mukono districts of Uganda: a cross sectional study. 13(1), 1-6.

Ojha, S. N., Tiwari, D., Anand, A., \& Sundriyal, R. C. (2020). Ethnomedicinal knowledge of a marginal hill community of Central Himalaya: diversity, usage pattern, and conservation concerns. J Ethnobiol Ethnomed, 16(1), 29.

doi:10.1186/s13002-020-00381-5

Pan, X., Zhang, A., Henderson, G. E., Rennie, S., Liu, C., Cai, W., Wu, F., \& Tucker, J. D. (2019). Traditional, complementary, and alternative medical cures for HIV: rationale and implications for HIV cure research. J Global public health, 14(1), $152-160$. doi:doi: 10.1080/17441692.2017.1413122

Phondani, P. C., Bhatt, I. D., Negi, V. S., Kothyari, B. P., Bhatt, A., \& Maikhuri, R. K. (2016). Promoting medicinal plants cultivation as a tool for biodiversity conservation and livelihood enhancement in Indian Himalaya. Journal of Asia-Pacific 
Biodiversity, 9(1), 39-46. doi:10.1016/j.japb.2015.12.001

Rahimi, A., Kassam, R., Dang, Z., \& Sekiwunga, R. (2019). Challenges with accessing health care for young children presumed to have malaria in the rural district of Butaleja, Uganda: a qualitative study. Pharm Pract (Granada), $17(4), 1622$. doi:10.18549/PharmPract.2019.4.1622

Rajeswara Rao, B. R. (2016). Genetic Diversity, Genetic Erosion, Conservation of Genetic Resources, and Cultivation of Medicinal Plants. In Genetic Diversity and Erosion in Plants (pp. 357-407).

Rakotoarivelo, N. H., Rakotoarivony, F., Ramarosandratana, A. V., Jeannoda, V. H., Kuhlman, A. R., Randrianasolo, A., \& Bussmann, R. W. (2015). Medicinal plants used to treat the most frequent diseases encountered in Ambalabe rural community, Eastern Madagascar. Journal of ethnobiology and ethnomedicine, 11, 68-68. doi:10.1186/s13002-015-0050-2

Rashrash, M., Schommer, J. C., \& Brown, L. M. (2017). Prevalence and Predictors of Herbal Medicine Use Among Adults in the United States. J Patient Exp, 4(3), 108-113. doi:10.1177/2374373517706612

Ross, I. A. (2007). Medicinal plants of the world, volume 3: Chemical constituents, traditional and modern medicinal uses (Vol. 3): Springer Science \& Business Media.

Shumba, E., Carlson, A., Kojwang, H., Sibanda, M., Masuka, M., \& Moyo, N. (2009). Traditional medicinal plant practice in southern Africa : a situational analysis in Zambia and Zimbabwe. Retrieved from

http://d2ouvy59p0dg6k.cloudfront.net/downloads/traditional_medicinal_plant_practice_regional_synthesis_report_new.pdf

Tabuti, J. R. S., Kukunda, C. B., Kaweesi, D., \& Kasilo, O. M. J. (2012). Herbal medicine use in the districts of Nakapiripirit, Pallisa, Kanungu, and Mukono in Uganda. Journal of ethnobiology, 8(1), 1-15. doi:https://doi.org/10.1186/1746-4269-8-35

The Plant List. (2021). The plant list Published on the Internet. Retrieved from http://theplantlist.org

Tugume, P., \& Nyakoojo, C. (2019). Ethno-pharmacological survey of herbal remedies used in the treatment of paediatric diseases in Buhunga parish, Rukungiri District, Uganda. BMC Complement Altern Med, 19(1), 353. doi:10.1186/s12906019-2763-6

Uganda Gazette. (2015). The Indigenous and Complementary Medicine Bill. Retrieved from http://parliamentwatch.ug/wpcontent/uploads/2016/10/

Uganda National Council for Science and Technology (UNCST). (2020). National guidelines for conduct of research during coronavirus disease 2019 (COVID-19) pandemic. . Retrieved from www.uncst.go.ug

UNCST. (2020). National guidelines for conduct of research during coronavirus disease (COVID-19) pandemic. Retrieved from www.uncst.go.ug

Wanjohi, B. K., Njenga, E. W., Sudoi, V., Kipkore, W. K., Moore, H. L., \& Davies, M. I. J. (2020). Ecological Knowledge of indigenous plants among the Marakwet Community (Embobut Basin), Elgeyo Marakwet County (Kenya). Ethnobotany Research and Applications, 20. doi:10.32859/era.20.1.1-16

WHO. (2013). WHO traditional medicine strategy: 2014-2023. Retrieved from https://www.who.int/medicines/publications/traditional/trm_strategy14_23/en/

World Health Organization. (2004). WHO guidelines on developing consumer information on proper use of traditional, complementary and alternative medicine: World Health Organization. 
Zerabruk, S., \& Yirga, G. (2012). Traditional knowledge of medicinal plants in Gindeberet district, Western Ethiopia. J. South African Journal of Botany, 78, 165-169. doi:https://doi.org/10.1016/j.sajb.2011.06.006

\section{Tables}

Due to technical limitations the Tables are available as a download in the Supplementary Files.

\section{Figures}

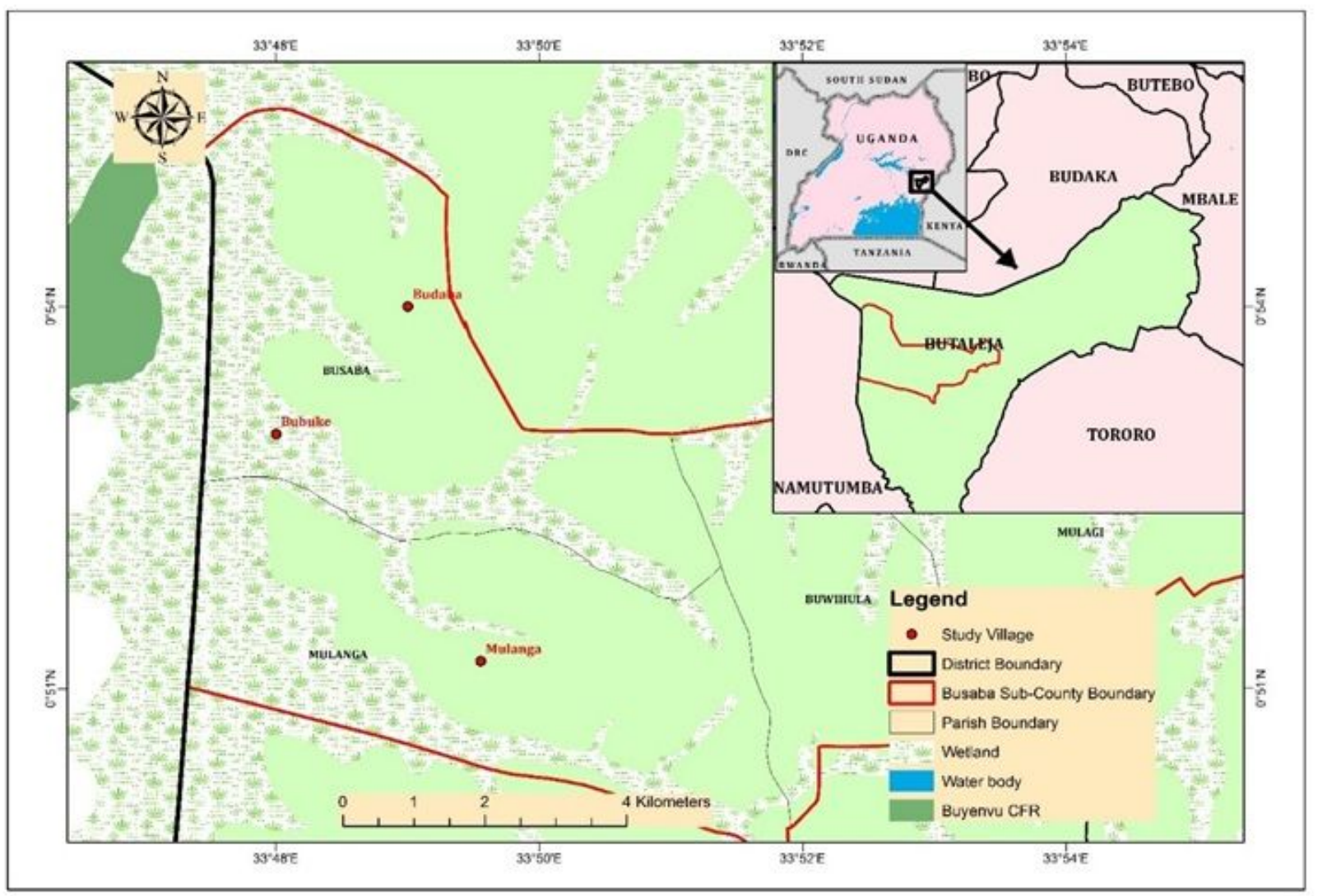

\section{Figure 1}

Location of the study area 


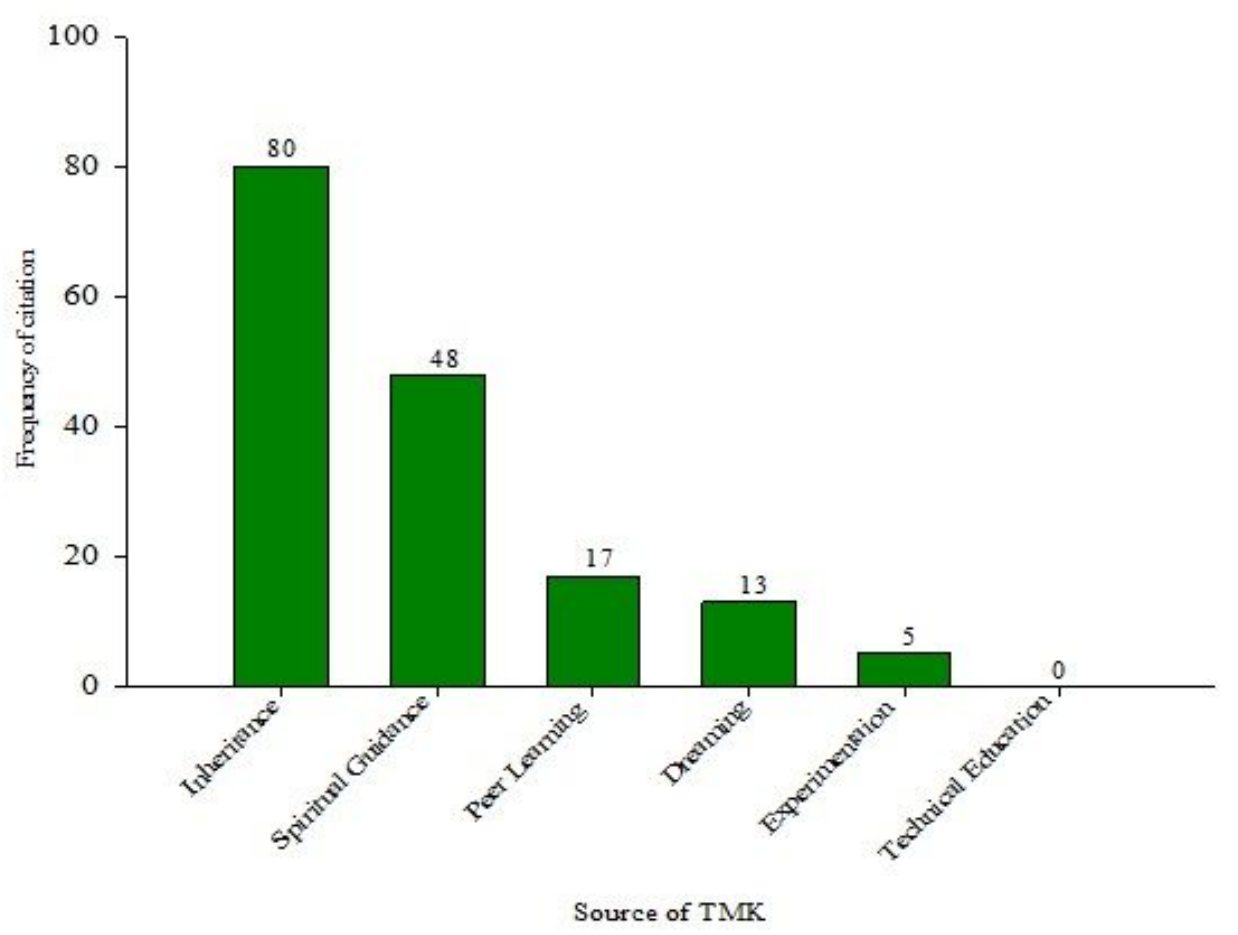

Figure 2

Sources of TMK among traditional medical practitioners in selected rural villages in Butalejja District, Eastern Uganda

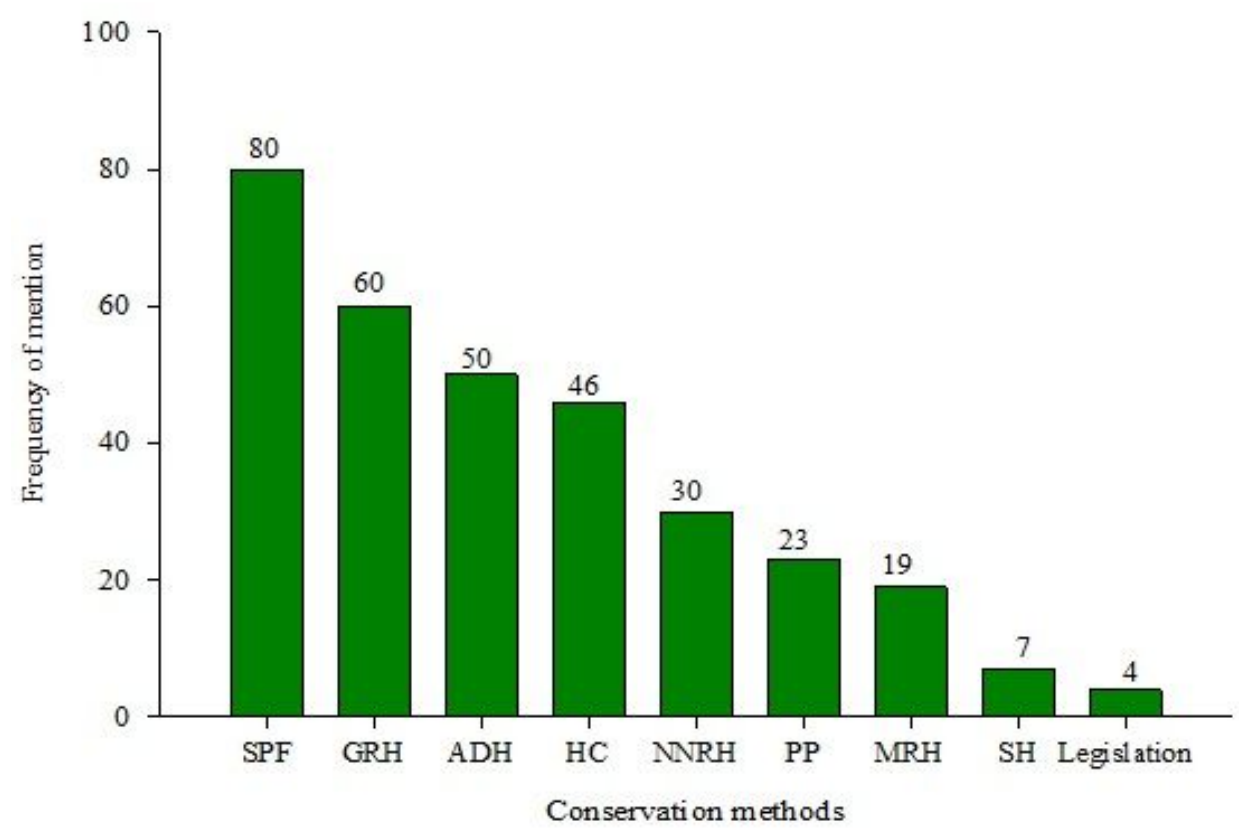

Figure 3

Conservation strategies of medicinal plants among traditional medical practitioners in selected rural villages in Butalejja District, Eastern Uganda. ADH=Avoiding Destructive Harvesting, PP= Preservation of Propagules, $\mathrm{SH}=\mathrm{Safeguard}$ from Herbivores, $\mathrm{HC}=$ Homestead Cultivation, $\mathrm{GRH}=$ Gender Restricted Harvesting, SPF= Spiritually Protected Forests (ENGOLO), $\mathrm{NMH}=$ Night and Naked Restricted Harvesting, and MRH=Mouth Restricted Harvesting 


\section{Supplementary Files}

This is a list of supplementary files associated with this preprint. Click to download.

- Tables12.pdf 